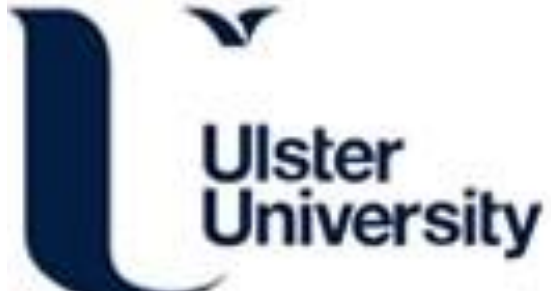

\section{The Role of an Electrolysis Reduction in Copper-Electroplating on Transparent Semiconductor Tin Oxide}

Liu, JS., Laverty, SJ., Maguire, PD., McLaughlin, JAD., \& Molloy, J. (1994). The Role of an Electrolysis

Reduction in Copper-Electroplating on Transparent Semiconductor Tin Oxide. Journal of the Electrochemical Society, 141(4), L38. https://doi.org/10.1149/1.2054872

Link to publication record in Ulster University Research Portal

\section{Published in:}

Journal of the Electrochemical Society

Publication Status:

Published (in print/issue): 01/01/1994

DOI:

10.1149/1.2054872

\section{Document Version}

Publisher's PDF, also known as Version of record

\section{General rights}

Copyright for the publications made accessible via Ulster University's Research Portal is retained by the author(s) and / or other copyright owners and it is a condition of accessing these publications that users recognise and abide by the legal requirements associated with these rights.

\section{Take down policy}

The Research Portal is Ulster University's institutional repository that provides access to Ulster's research outputs. Every effort has been made to ensure that content in the Research Portal does not infringe any person's rights, or applicable UK laws. If you discover content in the Research Portal that you believe breaches copyright or violates any law, please contact pure-support@ulster.ac.uk. 


\title{
The Role of an Electrolysis Reduction in Copper-Electroplating on Transparent Semiconductor Tin Oxide
}

\author{
J. S. Liu, S. J. Laverty, P. Maguire, J. McLaughlin, and J. Molloy \\ Department of Electrical and Electronic Engineering and Northern Ireland Bio-Engineering Centre, \\ University of Ulster, Jordanstown, Northern Ireland
}

\section{ABSTRACT}

An electroplating process has been employed to grow high-quality thin films of copper on tin oxide transparent semiconductor with excellent adhesion. It is shown that electrolysis reduction as a surface modification process prior to the electrodeposition is essential for good adhesion of the resulting copper coating. Experimental results obtained for electrolysis, argon plasma cleaning, and surface roughness measurements indicate that the formation of a monolayer of low valence tin oxide may be significant to the improvements in plating process and deposit adhesion. A mechanism whereby $\mathrm{SnO}_{x}$ formation may facilitate improved adhesion is proposed.

Tin oxide (TO) and indium tin oxide (ITO) are the most widely used materials for the front electrodes in flat panel displays including liquid crystal (LC), dc or ac-electroluminescent (EL), and plasma (PDP) displays. ${ }^{1}$ Response time, brightness uniformity, and power consumption depends critically on electrode line resistance, especially for large-area displays. At present, the best available ITO has $5 \Omega / \square$ at $90 \%$ transmittance with a thickness of $200 \mathrm{~nm}^{2}$ Compared to low resistivity metals such as copper $(\rho=2.1 \mu \Omega-\mathrm{cm})$ and aluminum $(\rho=2.8 \mu \Omega-\mathrm{cm})$, its resistivity $(\rho=100 \mu \Omega-\mathrm{cm})$ is two orders of magnitude higher. Conduction mechanisms in TO and ITO limits their intrinsic conductivities to about $2.5 \times 10^{6} \Omega^{-1}$ $\mathrm{m}^{-1}$. ${ }^{3}$ To achieve higher conductivity of the transparent electrodes, a combined electrode scheme using a thin high conductivity metal stripe in contact with the ITO or TO forming a hybrid electrode was proposed by Hope et al. ${ }^{4}$ Since then, there have been several reports ${ }^{5,6}$ based on this idea. In spite of their difference in structures, aluminum, which is vacuum evaporated, was always used as the metallic material due to its very low specific resistivity, ease of deposition, ready etching, and especially strong adhesion to $\mathrm{Si}$, $\mathrm{SiO}_{2}$, and many other oxide substrate materials. However, it is reported that the combination suffers severe corrosion when the combined conductor is cleaned in weak alkaline solutions, which causes disconnection and device failures. ${ }^{7}$ Furthermore, the contact resistance between aluminum and TO or ITO is quite high typically $80 \Omega$ for a contact area of $1.6 \times 10^{3} \mu \mathrm{m}^{2} .{ }^{6}$ At high temperatures, above $200^{\circ} \mathrm{C}$, which may be encountered in the fabrication process of subsequent layers such as $\mathrm{ZnS}: \mathrm{Mn}^{8}$ or during the device operation, ${ }^{9}$ the TO or ITO is readily reduced by aluminum via the formation of the more stable oxide, $\mathrm{Al}_{2} \mathrm{O}_{3 \cdot}{ }^{6}$ Copper $(\mathrm{Cu})$ is an attractive alternative and has been investigated for applications in interconnection formation. ${ }^{10} \mathrm{Cu}$ has lower resistivity than $\mathrm{Al}$ and is expected to be highly resistant to electromigration. ${ }^{11}$ In addition, $\mathrm{Cu}$ is less active than tin and therefore reduction of TO or ITO in contact with $\mathrm{Cu}$ at high temperature is less likely to occur. Usually a transition layer of $\mathrm{Cr}$ or $\mathrm{Ti}$, which are oxygen active metals, is needed in order to use copper on such substrates. However, in this case the introduction of such interface layers would significantly increase the contact resistance between the copper and TO substrates and is thus to be avoided.

The purpose of this paper is to describe the application of simple electroplating to the formation of adhesive thin films of $\mathrm{Cu}$ onto TO substrates without any transition metal layers.

\section{Experimental}

Glass substrates with a layer of chemical vapor deposited (CVD) tin oxide, approximately $8 \Omega / \square$ and $400 \mathrm{~nm}$ thick were used as samples. The samples were thoroughly cleaned using Balzers substrate cleaner 1,2 ; ultrasonically cleaning with Decon-90; deionized water rinsing; acetone dipping; $\mathrm{N}_{2}$ blow-drying, and then kept in the oven for later use. A 1.1 to $1.4 \mu \mathrm{m}$ layer of Dynachem OFPR800FP photoresist was deposited and exposed, using the mask pattern in Fig. 1 to get accurate data of plating current density. A solution of CuSO $_{4} \cdot 5 \mathrm{H}_{2} \mathrm{O}\left(180 \mathrm{~g} /\right.$ liter) and $\mathrm{H}_{2} \mathrm{SO}_{4}(0.6 \mathrm{M})$ was prepared for the plating bath. The surface roughness characteristic was obtained by stylus profiling using RTH Talystep and scanning electron microscopy (SEM) photographs. Thermal stressing of the samples by alternate immersion in boiling water and liquid nitrogen together with pulling by means of Scotch tape were used for adhesion testing.

\section{Results and Discussion}

The difficulties of plating copper onto planar tin oxide surfaces were quickly appreciated from preliminary experiments. At a wide range of plating bath voltage, from 0.2 to $1.6 \mathrm{~V}$, the plating process was very slow and the plated copper looked "burned" and powdery. The adhesion of the deposition was poor and readily finger-rubbed off.

An electrolysis reduction process prior to electroplating dramatically improved the quality of the subsequent depositions. The reduction process was proceeded in a solution of $0.01 \mathrm{M} \mathrm{Na}_{2} \mathrm{SO}_{4}$. $10 \mathrm{H}_{2} \mathrm{O}$ with $0.1 \mathrm{M} \mathrm{H}_{2} \mathrm{SO}_{4}$. The current density was nominally $25 \mathrm{~mA}^{2} \mathrm{~cm}^{2}$ with duration time of 5 to $10 \mathrm{~s}$. During the reduction, a thin black layer was formed and a rapid, brightening deposition was obtained on the treated samples. The adhesion of the deposition was also improved and no adhesion failure was found after either scratching or rubbing. This technique of prefacing the electroplating by an electrolysis reduction step has been used for conductivity enhancement of tin oxide electrode system in flat panel displays. In the conceptual structure of the conductivity enhancement technique shown in Fig. 2a, a thin layer of copper is plated to each vertical side wall of the conventional TO electrode before removal of the photoresist mask used to delineate the TO electrode structure. In this reduction/plating process the electrodes are connected in parallel to form the cathode. The SEM in Fig. $2 \mathrm{~b}$ shows a sample with $10 \mu \mathrm{m}$ wide sidewall copper buses plated on adjacent $200 \mu \mathrm{m}$ wide TO electrodes. Typical conductivity enhancement obtained by this structure as previously reported in Ref. 12 yields one order of magnitude improvement in electrode conductivity and minimal loss of transmission. Reasons for the improvements in both the plating process and the copper adhesion were investigated.

Process. - Two possible reasons for the improved plating process after an electrolysis reduction step are suggested and investigated.

1. The reduction process acts as a cleaning step just as in normal electroplating onto a metal base, in which a preplating reduction is suggested to remove the passive layer on the base metal surface. To test this effect, $\mathrm{Ar}$ ion plasma cleaning was used instead of electrolysis. The plasma conditions were 80 mTorr of pressure, input power of $300 \mathrm{~W}$, dc bias of $450 \mathrm{~V}$, and time duration of 5 to

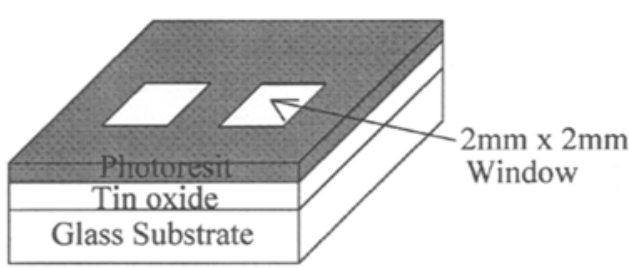

Fig. 1. Mask for copper electroplating. 

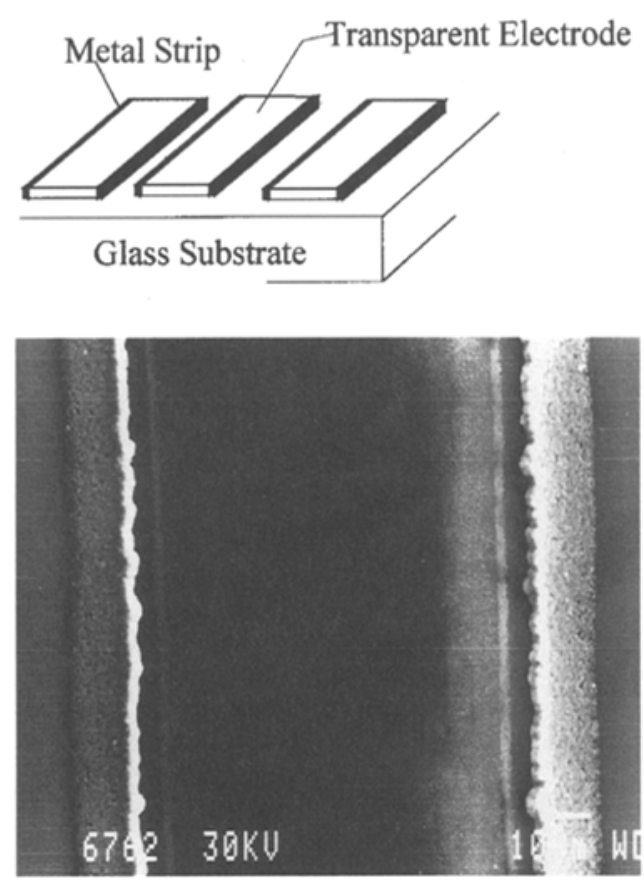

Fig. 2. Conductivity enhancement by widewall structure. (a, top) Schematic representation of conceptual structure for conductivity enhancement by wide wall plating. (b, bottom) SEM micrograph of plating on $200 \mu \mathrm{m}$ wide tin oxide electrodes showing $10 \mu \mathrm{m}$ copper sidewall buses.

$10 \mathrm{~min}$. However, the deposits on these plasma-treated samples were as poor as those untreated ones. Therefore, it is concluded that the reduction step does not function as a simple cleaning process.

2. The reduction step activated the sample surface by increasing the active area and/or decreasing the surface potential barrier of the $\mathrm{SnO}_{2}$ samples by chemically modifying its surface components so as to facilitate the transfer of electrons from $\mathrm{SnO}_{2}$ to discharged copper ions.

At the start of the plating process, a preferential deposition of metal occurs on separate portions of the surface of the cathode, $i, e$. , the active centers. As the grains of the deposited metal continue to grow, the separate portions of the deposit coalesce and the whole of the cathode surface becomes covered by the deposit. Therefore the more active points there are on the surface, the quicker the surface covering should be. This was confirmed by observing the size of the grown grain at the initial stage and the starting polarization potential of the sample cathode. Samples plated for $10 \mathrm{~s}$ were viewed under an optical microscope, and it was found that sparse and large grains formed on untreated samples while dense, fine ones formed on samples treated by the reduction process. The higher polarization was observed on untreated samples as well by using a reference electrode close to plating area. However, the mechanism by which the observed black layer contributed to the activation remains to be investigated

Adhesion.-As mentioned above, the adhesion of copper is always an essential issue when it is applied to these substrate materials. The prior reduction process also improved the adhesion of the deposited copper. Three possible explanations are considered.

1. The reduction process roughened the sample surface so that the enhanced mechanical interlocks between rough surface and deposited metallic atoms leads to improved adhesion. ${ }^{14}$ The surface roughness characteristics before and after reduction were measured by stylus profiling and SEM. No measurable change of sample surface roughness was observed. A typical set of observations is shown in Fig. 3. From the stylus measurement, it can be seen that the roughness of the sample surface is less than $10 \mathrm{~nm}$. Thus this mechanism of adhesion is discounted.

2. Normally strong alloy bonding between different metals are easily formed. Therefore, it may be that metallic tin is generated during reduction which results in the formation of a tin-copper bond subsequently leading to improved adhesion. The metallic state of tin was observed in the black reduction products by heating the samples above the tin melting temperature, whereupon small tiny tin spheres were seen under an optical microscope of magnification of 560 times. The existence of metallic tin in reduction products was also observed by others. ${ }^{13}$ Unfortunately, for this hypothesis the black products readily dissolve in acid solutions including the plating solution. Therefore the acid copper plating bath might influence the integrity of the black layer before the starting of plating. It was found that samples prepared with the black layer removed by acid solution immediately before plating were of equal uniformity and adhesion compared to that achieved when no action to remove the black layer is taken. Thus it is likely that this layer and the metallic tin play little or no part in the process, they being intrinsically removed in the acidic plating process.

3. The formation of a monolayer of low valence of tin oxide, $\mathrm{SnO}_{x}$, during reduction is another possible reason for the improved adhesion. Before the reduction process, the surface of tin oxide samples is as that in Fig. $4 a^{15}$ in which a tin atom is in full chemical valence state with oxygen. For copper electroplated onto this kind of surface, the deposited copper atoms, due to the low oxygen activity of copper, are just adsorbed on the surface by Van der Waals force, which is small and approximately $0.4 \mathrm{eV} .^{16}$ However, if the samples were modified by an electrolysis reduction, a monolayer of $\mathrm{SnO}_{x}$ may be formed on the surface. Then the deposited copper atoms would form a much stronger bond with $\mathrm{Sn}(\mathrm{II})$, which would contribute to the improved deposition adhesion.

To test this, the reduction treated samples were immersed into $\mathrm{H}_{2} \mathrm{SO}_{4}$ solution of $3 \mathrm{~N}$ to remove the black layer prior to the plating with all of the metallic tin in the reduction products dissolving in the
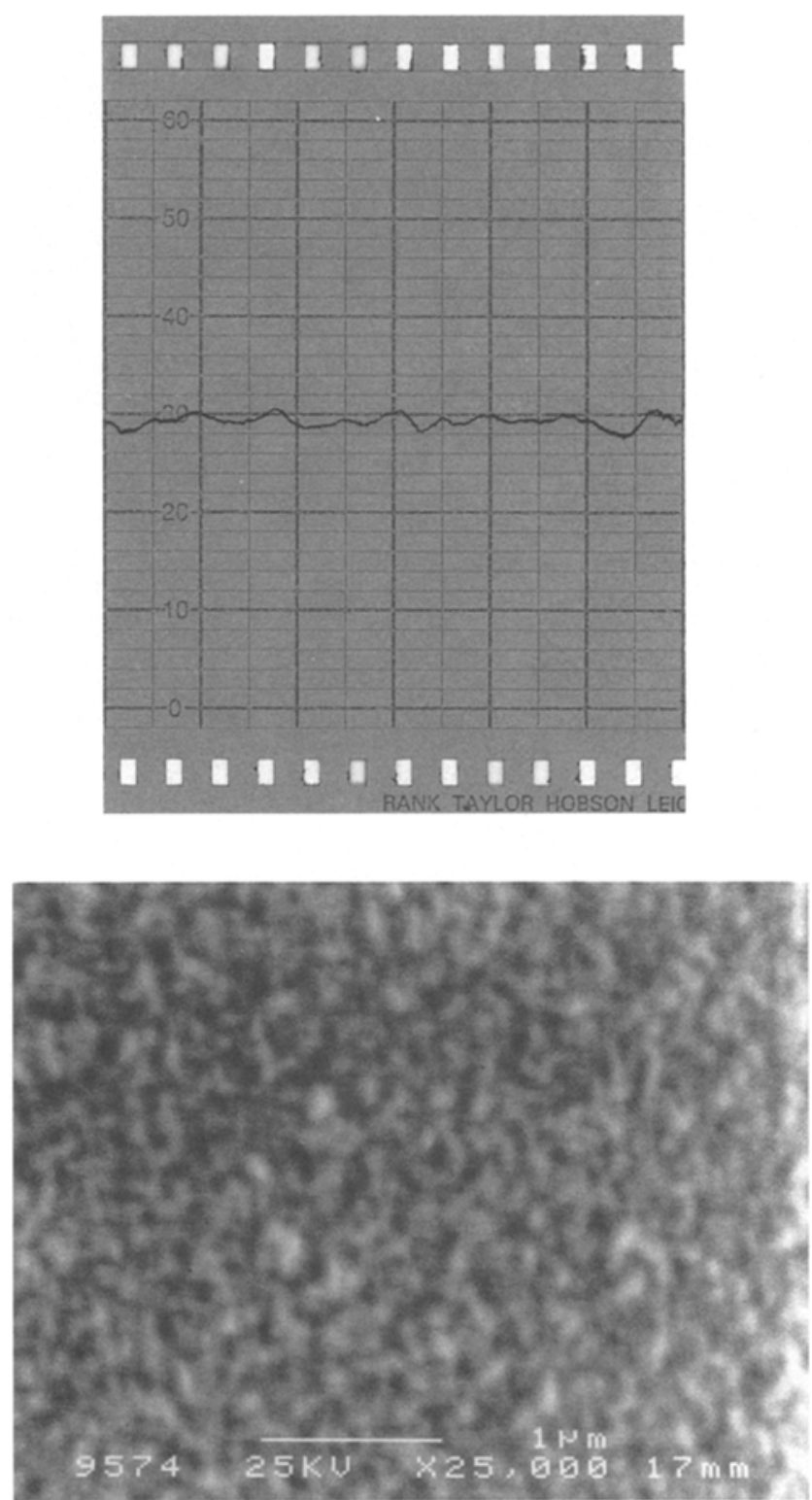

Fig. 3. Roughness measurements of tin oxide surface. (a, top) Stylus profile obtained by Talystep. Unit: $4 \mathrm{~nm} / \mathrm{mm}$. (b, bottom) SEM micrograph of surface. 


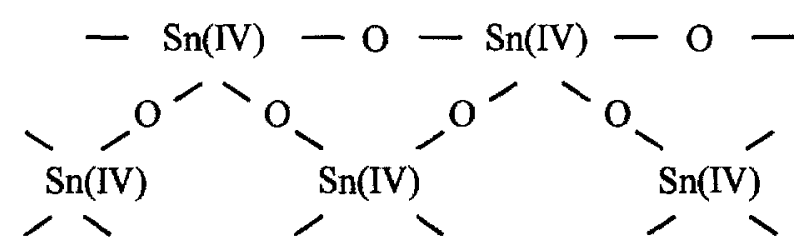

(a)

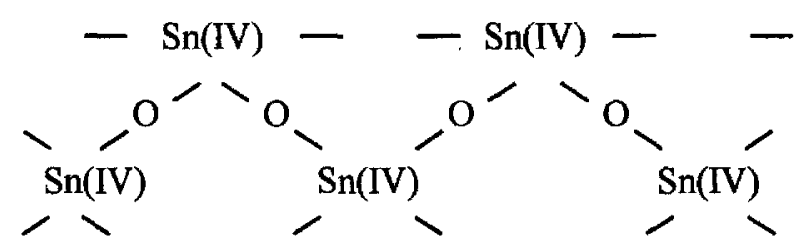

(b)

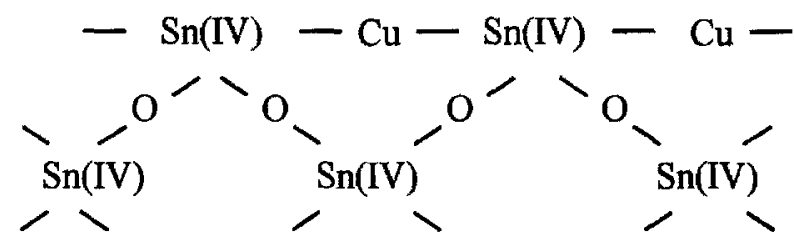

(c)

Fig. 4. The proposed effect of reduction on deposition adhesion: (a) before reduction, (b) after reduction, and (c) coating on a modified surface.

acid. The effect of tin on the subsequent deposits is ignored. A wide range of plating current densities from 32.5 to $150 \mathrm{~mA} / \mathrm{cm}^{2}$ were applied. The adhesion of the deposited film was tested by Scotch tape and thermal stress alternately. Good results were obtained and the deposition stood up to the peeling test. Quantitative adhesion tests and the $x$-ray photon spectroscopy surface component analysis are continuing.

\section{Conclusion}

Conductivity enhancement of the transparent conductor electrode system used in flat panel displays is necessary due to the requirement of response speed and power consumption. The normally poor adhesion of copper onto this substrate material prevents its application in combined electrode structures. Copper electroplating has been demonstrated to give good adhesion of copper deposits on $\mathrm{SnO}_{2}$ substrates. A prior electrolysis reduction process was shown essential in this technology, which improved the plating process and deposition adhesion. While conclusive evidence of the formation of low valence tin oxide is not yet available, the formation of such a surface layer by the necessary electrolysis stage is proposed as a plausible mechanism for the improvements observed.

\section{Acknowledgments}

The assistance of the following institutions is gratefully acknowledged: Department of Chemistry, University of Ulster; the Microscopy Unit (Queens University, Belfast), and the British Council.

Manuscript submitted Oct. 12, 1993; revised manuscript submitted Feb. 4, 1994.

The University of Ulster assisted in meeting the publication costs of this article.

\section{REFERENCES}

1. H. L. Snyder, Flat Panel Displays and CRTs, Van Reinhold Company, New York (1985).

2. T. Braguier and M. Braguier, Thin Solid Films, 80, 143 (1981).

3. J. R. Bellingham, W. A. Phillips, and C. J. Adkins, J. Mater. Lett., 11, 263 (1992).

4. L. L. Hope, J. L. Plumb, and D. H. Baird, in Proceedings of International Conference, Japan Displays '83, p. 582 (1983).

5. R. O. Tornqvist, et al., SID '91 Digest, p. 63 (1991).

6. O. J. Gregory, R. J. Zeto, E. Hryckowian, and K. A. Burbank, This Journal, 138, 1943 (1991).

7. J. E. A. M. Van Den Meerakker and W. R. Ter Veen, ibid., 139, 385 (1992)

8. C. A. Parker, Photoluminescence of Solutions, Elsevier Pub. Co., Amsterdam (1968)

9. M. P. R. Panicker and W. F. Essinger, This Journal, 128, 1943 (1981).

10. T. Ohmi, T. Saito, T. Shibata, and T. Nitta, Appl. Phys. Lett., 52, 2236 (1988)

11. T. Ohmi, T. Saito, M. Otsuki, T. Shibata, and T. Nitta, This Journal, 138, 1089 (1991).

12. J. S. Liu, S. J. Laverty, P. Maguire, J. McLaughlin, J. Molloy, and J. Anderson, SID '93 Digest, p. 63 (1991).

13. N. R. Armstrong, A. W. C. Lin, M. Fujihira, and T. Kuwana, Anal. Chem., 48, 741 (1976).

14. N. Inagaki, S. Tasaka, and K. Hibi, J. Polym. Sci., Part A: Polym. Chem., 30, 1425 (1992).

15. P. Kirkov, Electrochim. Acta, 17, 519 (1972).

16. S. Wolf and R. N. Tauber, in Silicon Processing for the VLSI Era, Vol. 1: Process Technology, p. 113, Lattice Press. 